\title{
Opportunities for Market Repositioning of Divergent Eco-Tourist Products in a Dynamic External Environment
}

\author{
Chief Assist. Prof. PhD Todor Dyankov \\ University of Economics - Varna, Varna, Bulgaria \\ todordyankov@ue-varna.bg \\ Senior Prof. Yuliyana Todorova \\ University of Economics - Varna, Varna, Bulgaria \\ ju19de65@ue-varna.bg
}

\begin{abstract}
The article aims to outline specific opportunities for market repositioning of eco-tourist products in conditions of strongly dynamic external environment. In reference to this, authors' own research approach has been used for generating creative suggestions by way of divergence. In the research experiment there took part students - future experts in the field of tourism, who are close to the modern interpretation of the threats and opportunities stemming from an ecologically problematic external environment.
\end{abstract}

Keywords: divergent thinking, market repositioning, dynamic external environment, eco-tourist products

JEL Code:A00; doi:10.36997/IJUSV-ESS/2019.8.3.111

\section{Introduction}

The tourist industry involves an enormous number of people satisfying their needs and wants for travelling by contributing to the world economy significant output of benefits. Respectively, the tourist activities create jobs and employment for millions of individuals worldwide which affirms tourism as a more significant sector in the economies of many countries that rely increasingly on the services industry. On the other hand, the tourism sector is inevitably bound to the external environment and the related environmental problems for the elaboration of adequate regulative issues. Today, the development of eco-tourism and its products face new challenges about the rising multifaceted discussions on the external environment. It is evident that the diversification process of eco-tourist products has to continue in order to keep in pace with the dynamics of this environment. Changes of notions, changes of products and changes of market perceptions about products and processes are in the sheer basis of a necessary shift of eco-tourism from its current status towards the requirements of the coming future. In this way of thinking the research goal of the article is to outline specific opportunities for market repositioning of eco-tourist products in the context of strongly dynamic external environment.

\section{Eco-tourism - the need for market repositioning}

Staying away from the widely spread, and at the same time, naïve "gretenism", it is beyond any doubt that the world does not look like the way it used to be 10 years ago (https://www.climatedepot.com/). Nowadays humankind is facing huge challenges as a result of climate changes. Fig. 1 shows the striking gap between climate action goals and the reality which presupposes the urgency of profound social and economic transformations in order to avert the dangerous temperature increase worldwide and possibly prevent its irreversible impacts.

There are five serious issues in socio-economic aspect that, if not solved in time, can easily turn into a grave threat for the environment. These are air pollution, deforestation, the extinction of animal and plant species, soil erosion and global overpopulation.

A consequence of the huge quantities of carbon dioxide is the even higher degree of temperature of the ground and sea water. The main reason for air pollution is the excessive content of $\mathrm{CO}_{2}$. According to data of the World Health Organization, there are an increasing number of cases of diseases due to substances in the polluted air causing cancer. 


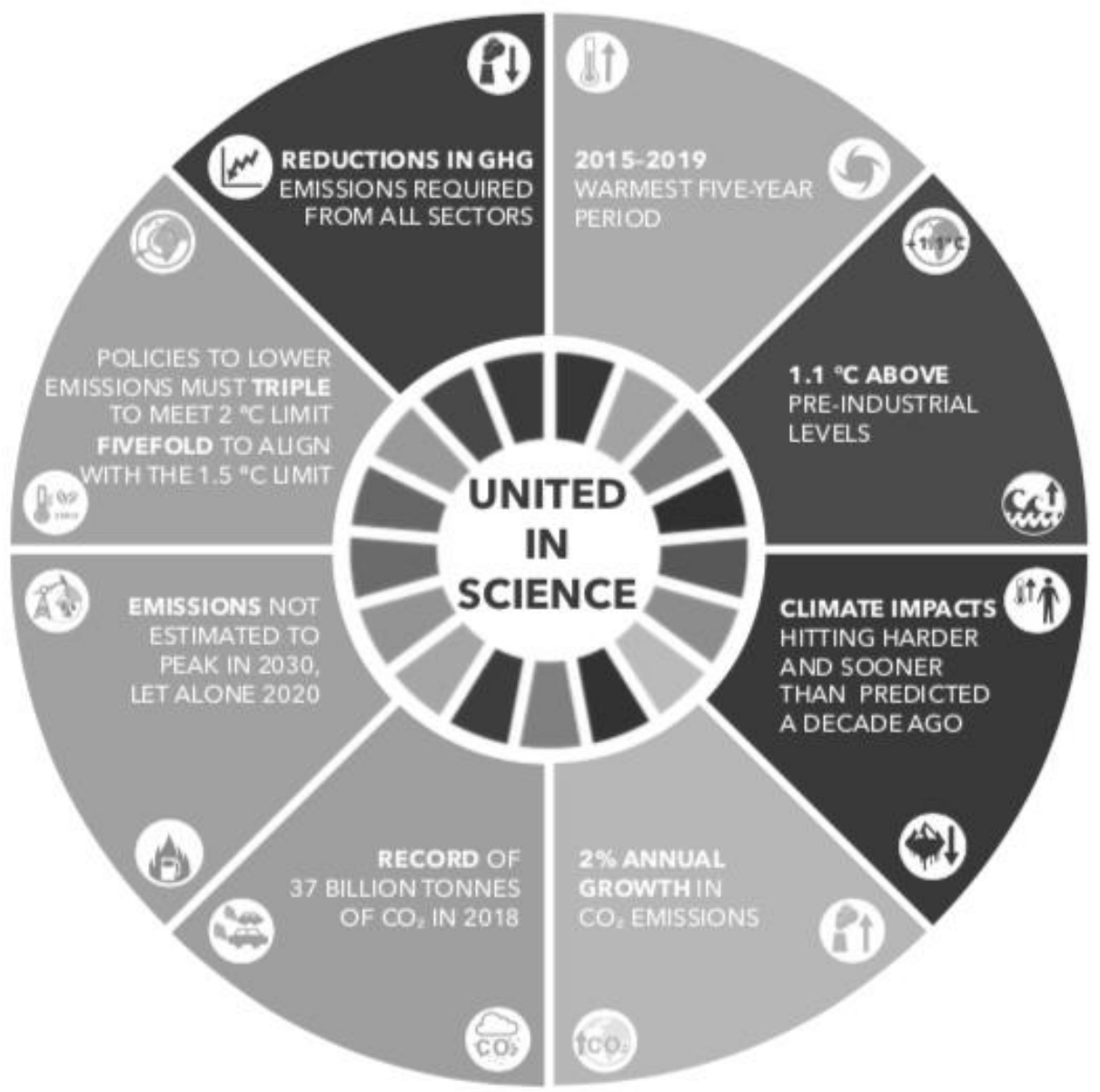

Figure 1: Action goals and the reality as a result of climate changes

Source: Climate Action Summit, Sept.2019, NYC https://news.un.org/en/story/2019/09/1046972

The problem of deforestation has spread globally as well. Today only $30 \%$ of the earth surface has been forested which is only half of the quality of what used to be 11000 years ago. Compared to the former tropical forests on $15 \%$ of the earth surface, today it accounts for not more than 6-7\% and most of it has been mercilessly cut down or purposefully burnt out.

The third serious complication concerning the environment is the considerable loss of biodiversity which also requires immediate measures. In Africa, it could cause some animals to decline by as much as 50 percent by the end of the century, and up to 90 percent of coral reefs in the Pacific Ocean may bleach or degrade by the year 2050.

Erosion, excessive use of harmful substances and turning green areas into agricultural lands are another serious trial faced by people today. The loss of trees and other vegetation indisputable leads to desertification, soil erosion, less crops, more flooding and greenhouse gasses in the air, as well as a number of problems for indigenous people.

Last but not least is the issue of uncontrollable overpopulation globally. In the beginning of $20^{\text {th }}$ century there were 1.6 bn people on earth, whereas today the number is more than 7.7 bn and the figure could reach $10 \mathrm{bn}$, considering the fastest rate of increase being in Africa, Southern and Eastern Asia. Respectively, the bigger number of population and the increasing living standard exert a serious pressure on vital natural resources as water, for example.

The reality of the modern external environment described above adds extra need for developing eco-tourist products and arousing the awareness of future specialist in the field of 
tourism. It is them who, hopefully, will be the supporters and doers of decoupling economy - whose growth does not occur at the expense of destroyed environment. In this relation eco-tourism has become an active field of revival of the sustainable connection between the social needs and the external environment. For that reason today we may witness the process of conversion of ecotourist products from business and destination levels to environmental conservation, preservation practices and even eco-innovations (Garrillo - Hermosill, J. et al., 2009). Now more than ever there is a need of new ways and means of communication of eco-tourist products going beyond the simple practices of eco-labelling in tight coherence with communication of environment issues (Sunnetcioglu, S. et al., 2016). This new reality requires the relevant market repositioning of ecotourist products. Here the general task is how to implement a major change in the perceptions of target markets about the key benefits and features of eco-tourist products in reference not only to the offerings of other competitive products but also in full compliance with the demanding external environment.

\section{Ways of going divergent for market repositioning}

The actual challenge to stay competitive on the market is highly related to the concepts of generating creativity process for market repositioning purposes. In reference to this the scientific publications in the field of creativity could be related to four types of thinking processes: linear, lateral, radiant and divergent. The linear (one-dimensional) type of thinking, which is actually vertical, is based on cause-and-effect logics, critical reasoning and judgement. It is characterized by moving in one direction, following a certain sequence, giving argumentation for each step, aspiration to make choices by way of elimination, reaching a final process or a sense of completing a particular action (Kotler, Ph. and Trias de Bes, F., 2003). The linear type of thinking is also called convergent - a process of naming existing concepts and ideas from a certain field of knowledge that act as a ground for making optimal decisions to solve a particular problem. On the whole, it is accepted that linear presentation supports creative thinking, however, it can also hamper it (Buzan, T. and Buzan, B., 1996). The lateral (two-dimensional) type of thinking as a kind of innovative approach follows three basic steps: choosing a focus, creating a horizontal shift in order to bring in a stimulus - the so-called "disruption" or "interception" and making a connection. Lateral thinking is considered to be provocative, aiming at discovering various directions, a number of alternatives and possibilities, transcending beyond what is known, obvious and satisfactory (De Bono, E., 1985). The basic method of creating a provocation is the use of the so-called "random word", meaning that there is no direct link between the problem or issue assigned for research.

Radiant thinking is associated with mental processes coming from or referred to a central point and disseminated in all directions. The material manifestation of this type of thinking is the pattern of the established mind map (mental map) that is always laid out around a focal notion. Each word or image, in turn, becomes a secondary centre of associations and this gives the start of a theoretically endless network of dividing data systems coming from or aiming at a single nucleus or centre. In this line of thinking the mind map can be presented in a multi-dimensional reality by including space, time and colours. Mind maps are defined as a step in the transition from linear (one-dimensional) through lateral (two-dimensional) to radiant or multi-dimensional type of thinking.

Divergent thinking manifests itself when preliminarily disconnected areas and contextual spheres of knowledge are bound in ways that can lead to creating something unusual, innovative and different (Smith, R.E., et al., 2007). Combining lateral and radiant thinking underpins the divergent approach which is based exclusively on the creative type of thinking. In academic 
literature the views on creativity vary in broad dimensions - from focusing on separate components as individuality, novelty, extraordinariness, significance, connection and others to a comprehensive unity of a multitude of elements (Ang, S.H. and Leong, S.M., 2007).

Creativity in integrated marketing communications for the purposes of market repositioning, has the potential to have an impact on the end consumer - the tourist, in several trends (Eagle, L, et al., 2015). It is thought that creativity increases the chance for target audiences optimally well to notice the message that will also lead to being effectively perceived by them. Thus there are reported promising outcomes too for overcoming the filtrating mechanisms of consciousness, namely - the consumer's perceptive selectivity and perceptive vigilance. The application of creativity increases the possibility for the target audience to support a particular advertising campaign once it has accepted the communicated message. Last but not least, significant studies on the topic of creativity point out that using it in integrated marketing communication strategies facilitates the process of remembering the message on behalf of the audiences (Till, B.D. and Baack, D.W., 2001).

\section{Research method}

The research method is based on the exploitation of radiant thinking in combination with a lateral approach for eliciting by way of divergence new product opportunities apt for repositioning purposes in the field of eco-tourism. The research process is carried out in four experimental groups of participants - actively enrolled 3rd year university students in the field of tourism. This group of participants was intentionally chosen for the reasons of obtaining semi-professional as well as semiconsumer opinions, respectively visions on the researched problem.

Each of the participants in the experimental group takes part in creating one's individual mind map which is spread out on three stages (levels), with a starting (central) category serving as a reference point for ensuing associations with eco-tourism.

During the first stage of mind mapping, students were asked to provide their initial 10 direct associations with the central category "eco - tourism" by typing them along the drawn radians. In this occasion it is scientifically proved that typing words prevents students from mechanistic elicitation of propositions and at the same time it guarantees a higher level of awareness of the processed outcomes.

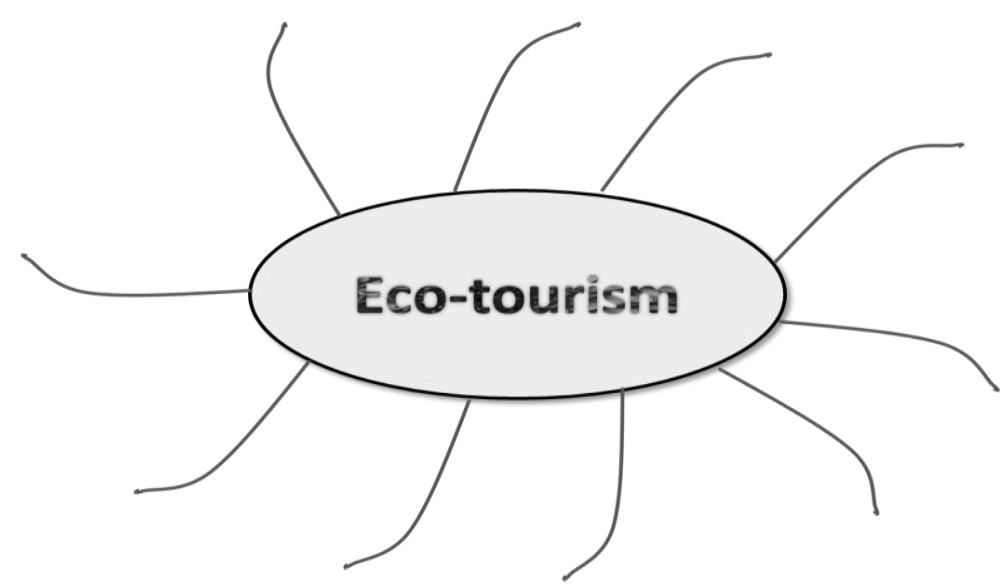

Fig.2 First stage of mind mapping

The second stage of mind mapping is a logical continuation of the initial process of associations. At this part of the experiment participants were asked to suggest separate batches of 3 
additional associations with relation to the initially proposed associations. Once again the hand typing of associations is required.

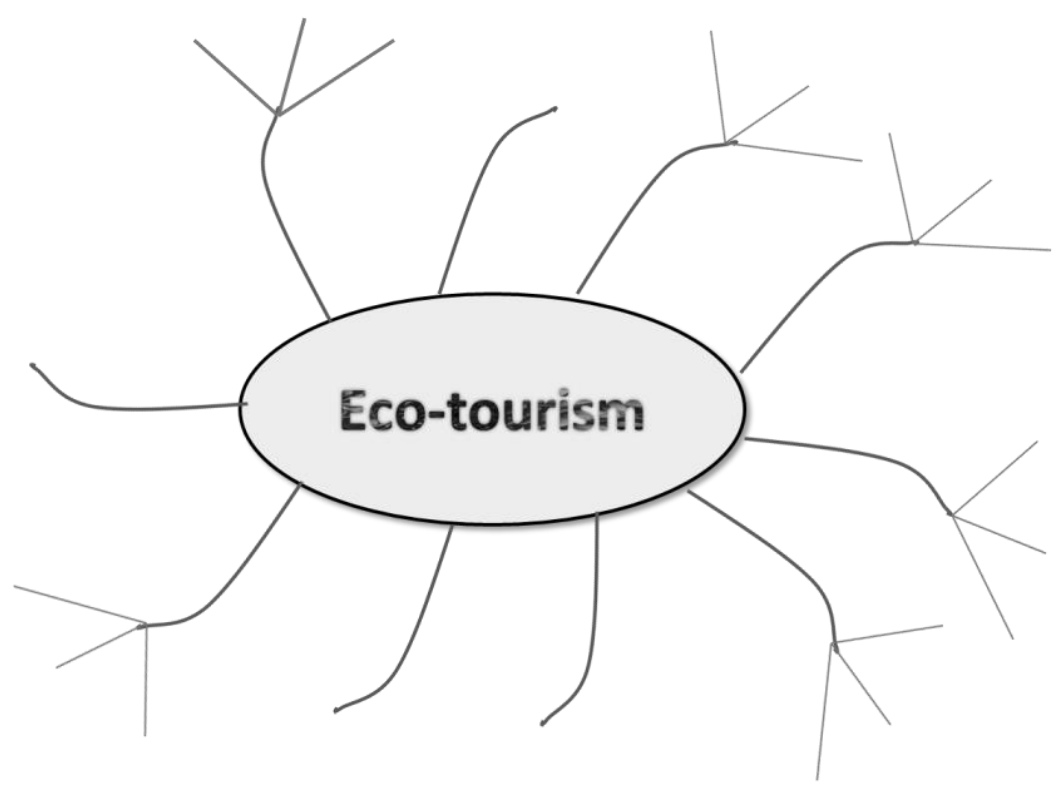

Fig. 3 Second stage of mind mapping

The last stage of mapping is about searching ways of side (lateral) connections between logically disconnected characteristics (categories) that are brought to by way of association in the first two stages. In this relation students were asked to determine and trace out on their individual mind maps the connections of logically disconnected categories in all possible directions. The general assumption here is that the central category eco - tourism should not be included in the process of searched connections. Adjacent categories of vertical (linear) connections are also excluded from the process of connectivity.

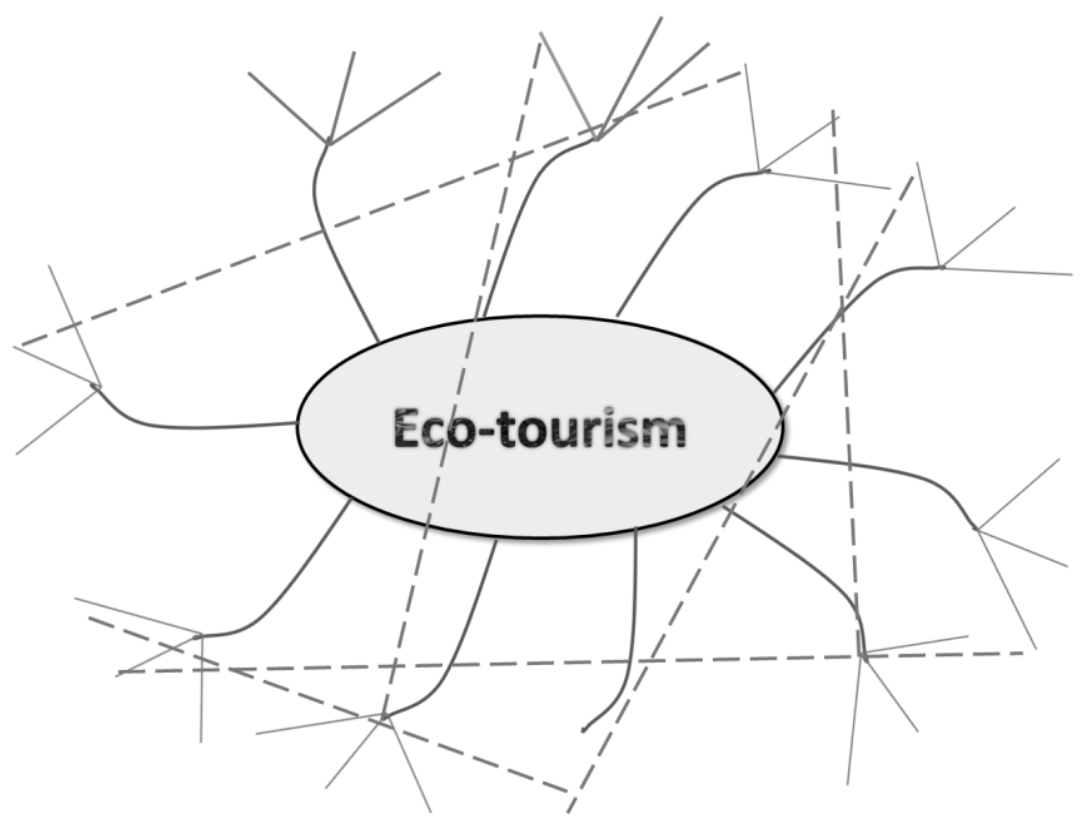

Fig. 4 Third stage of mind mapping 
After the completion of the mind mapping comes the stage of the group discussion of suggestions for eliciting verbal pairs of evidently disconnected categories and selecting those of them which have seemingly the highest degree of absurdity in meaning. The selection of pairs of categories was based upon mutual consent amongst students as a result of the group discussion. The very last stage of the experiment was about asking the participating students to produce divergent suggestions concerning the selected pairs of categories. After having been outlined those divergent suggestions serve as a creative platform for the formulation of new product opportunities in the field of eco-tourism which were also ensuing from the creativity thinking of students at the very end of the experiment.

\section{Results and discussion}

The obtained results were analyzed by groups of participating students. Each group consisted of between 8 and 13 participants - enough as a quantity number for the accurate implementation of the experiment. The experimental process was entirely mediated during the seminars in class separately for each academic group of students starting from the procedures of mind mapping until the final stage of students' provision of new product opportunities based on the revealed divergent suggestions.

The empirical results relating the number of groups to the total number of produced logically disconnected pairs and the relevant content of outlined divergent suggestions are presented in Table 1.

Table 1. Participants and results in the research experiment

\begin{tabular}{|c|c|c|c|}
\hline $\begin{array}{l}\text { Experimental } \\
\text { group }\end{array}$ & $\begin{array}{l}\text { Number of } \\
\text { students }\end{array}$ & $\begin{array}{c}\text { Total number of } \\
\text { logically } \\
\text { disconnected } \\
\text { pairs }\end{array}$ & $\begin{array}{c}\text { Content of outlined divergent } \\
\text { suggestions }\end{array}$ \\
\hline Group One & 12 & 25 & $\begin{array}{l}\text { „sea - fireplace“" } \\
\text { „ax - oxygen" } \\
\text { „dream - waterfall“" } \\
\text { „smell - inner "I" } \\
\text { "grandmother's dishes - axis" } \\
\text { „wave - door" }\end{array}$ \\
\hline Group Two & 8 & 26 & $\begin{array}{l}\text { "green - snow" } \\
\text { „waste - vitamins" } \\
\text { „children - fresh" } \\
\text { „teeth - waterfall“" } \\
\text { "grandmother's garden- volcano" } \\
\text { „petrol - teeth" }\end{array}$ \\
\hline Group Three & 9 & 21 & $\begin{array}{l}\text { „anti GMO - sunset" } \\
\text { „therapist - recycling“" } \\
\text { „waterfall - equality“" }\end{array}$ \\
\hline Group Four & 13 & 25 & $\begin{array}{l}\text { "headache - fish“" } \\
\text { „wind - banana“" } \\
\text { „soup - sunset“" } \\
\text { "ski - beach“" } \\
\text { „snowdrop - fresh“" } \\
\text { „white socks- elephant“" }\end{array}$ \\
\hline
\end{tabular}

Source: the authors 
Based on the content of the revealed divergent suggestions students from each group have come individually in class to the final elaboration of divergent opportunities for repositioning of eco - tourist products as it follows:

For experimental group one:

- The smell (scent) as a reason and transmitter for rediscovering one's inner "I"

- Ecotourism as a purifier of human perceptions

- A process of natural baking of a restaurant product

- Recharging one's batteries through outdoor activities

- Feeling better by way of glass

- Peace and serenity as a result of transforming elements

For experimental group two:

- Processing waste food into vitamins (zero waste)

- „Fresh“ eco-tourists

- The elements of nature for improving one's health

- Eco-tourism for creating a new generation

- From unthinkable to possible cleanness

For experimental group three:

- Recycling as a therapy in eco-tourism

- Everybody is equal before the elements of nature

- A balance in the natural element

For experimental group four:

- Food and protection

- Driving force for an eco-tour

- Eating contemplation

- Integration in the simplicity of locality

- Laterality in revealing the essence

In general it is observed that students creative opinions extracted by way of divergence tend to spontaneously gravitate towards a unifying thematic content within each experimental group. Having in mind the mediated individual work of students in class, their relatively independent participation is partly influenced by the group discussion for outlining divergent suggestions as well as partly influenced by their additional verbal and non-verbal communication issues in situ. This finding does not diminish the importance of individual student creativity drawn in a divergent way to reveal new opportunities for repositioning of eco-tourist products. In this relation it could be implied that the first experimental group of students stands more about the idea of eco-tourism in harmonies and transformations, focusing on the social process of things to happen. The second experimental group is mostly bound to the idea of eco-tourism in processing and new outsets - the way of doing the things. Eco-tourism as a medium of functioning forces is more inherent for the reposition visioning of the third group, while the fourth group is sharing the opinion for new ecotourism products in the hedonism of staying and eating.

\section{Conclusion}

In a world of strong disturbances and deteriorated external environment it is getting harder to untap the additional potential of eco-tourist product issues. The contemporary circumstances of human development require tourist companies to stay competitive on the market place in a full 
accordance with the dynamic external environment. The lack of sufficient creative options has become a real managerial and marketing problem for repositioning of companies and products. For that reason this article empirically proves that real opportunities for making creative breaks in the conventional reality do exist right in front of us. In this line of thinking we may state that implementing specific methods of divergence is a reliable basis for obtaining diversified marketing decisions for successful repositioning of innovative eco-tourist products towards existing or brand new markets. One just have to take the risk of starting to be divergent.

\section{References}

1. Ang, S.H., Lee, Y.H. and Leong, S.M. (2007) The ad creativity cube: conceptualization and initial validation. Journal of the Academy of Marketing Science, 35 (2), pp. 220 - 232

2. Buzan, T. and Buzan, B. (1996) The Mind Map Book: How to Use Radiant Thinking to Maximize Your Brain's Untapped Potential. Plume, p. 21

3. De Bono, E. (1985) Six thinking hats. Little brown and company, p. 174

4. Eagle, L. and others. Marketing communications. Routledge, 2015, p.96

5. Garrillo - Hermosill, J. et al. (2009) Eco-innovation. When sustainability and competitiveness shake hands. London: Palgreve, McMillan

6. Kotler, Ph. and Trias de Bes, F. (2003) Lateral marketing. Wiley \& Sons, p. 91

7. Smith, R.E., Mackenzie, S.B., Yang, X., Buchholz, L. and Darley, W.K. (2007). Modelling the determinants and effects of creativity in advertising. Marketing Science, 26 (6), pp. $819-833$

8. Sunnetcioglu, S. et al. (2016) Eco-labelling at restaurants: case of green generation restaurants program. The $6^{\text {th }}$ international scientific conference changes in social and business environment, 28 - 29 Apri 2016, Panevezys, Lithuania, pp. 51 - 57

9. Till, B.D. and Baack, D.W. (2001) Recall and persuasion: does creative advertising matter? // Journal of Advertizing, 34 (3), pp. 47 - 57

10. https://academic.oup.com/bioscience/advancearticle/doi/10.1093/biosci/biz088/5610806?search result $=1$

11. https://www.climatedepot.com/2019/07/23/physicist-some-climate-alarmists-embrace-chemtrails-claim-govts-are-adding-these-chemicals-to-harm-the-population-or-make-it-obedient-orsomething-like-that/

12. https://www.coe.int/bg/web/compass/environment

13. http://meteorology.meteo.bg/bro6ura.pdf

14. https://news.un.org/en/story/2019/09/1046972 